\title{
Episclerite e esclerite
}

\author{
Episcleritis and Scleritis
}

\author{
Andréia Peltier Urbano ${ }^{1}$ \\ Alessandra Peltier Urbano ${ }^{2}$ \\ Ivan Urbano ${ }^{3}$ \\ Newton Kara-José ${ }^{4}$
}

${ }^{1}$ Médica Residente da Universidade Estadual de Campinas - UNICAMP

${ }^{2}$ Acadêmica de Medicina da Universidade Federal da Bahia - UFBA.

${ }^{3}$ Diretor Médico da CLIVAN- Instituto de Oftalmologia ${ }^{4}$ Professor Titular de Oftalmologia da Universidade Estadual de Campinas-UNICAMP e Universidade São Paulo-USP.

Endereço para Correspondência: Rua Napoleão de Barros, 1058/22 - São Paulo (SP) CEP 04024-003.

E-mail: andreiaurbano@uol.com.br

Recebido para publicação em 24.01.2002

Aceito para publicação em 10.08.2002

\begin{tabular}{|c|}
\hline RESUMO \\
\hline As doenças mais freqüentes da esclera são de caráter inflamatório, sendo \\
divididas em episclerite e esclerite. A episclerite é doença benigna, \\
autolimitada, com inflamação do tecido episcleral superficial, ao passo que \\
a esclerite é doença grave, progressiva, com inflamação dos tecidos \\
episcleral superficial, profundo e escleral. A associação da episclerite e \\
esclerite com doenças sistêmicas reumatológicas requer investigação \\
sistêmica dos pacientes com inflamação escleral.
\end{tabular}

Descritores: Esclerite/diagnóstico; Esclerite/quimioterapia; Inflamação; Esclera/patologia; Infecções oculares bacterianas/diagnóstico; Infecções oculares bacterianas/quimioterapia; Doenças auto-imunes/diagnóstico; Artrite reumatóide/complicações; Corticosteróides/uso terapêutico; Prednisolona/ uso terapêutico; Diagnóstico diferencial; Resultado de tratamento

\section{ANATOMIA E FISIOLOGIA}

A esclera constitui os $5 / 6$ posteriores da túnica externa do globo ocular, com conformação esférica de $22 \mathrm{~mm}$ de diâmetro. Apresenta um orifício anterior que se continua com a córnea e um posterior para entrada do nervo óptico. Sua espessura é variável a depender do ponto anatômico: próximo ao nervo óptico - $1 \mathrm{~mm}$; equador - $0,5 \mathrm{~mm}$; anterior - $0,8 \mathrm{~mm}$; porção posterior das inserções dos músculos retos - 0,2 mm.

As camadas da esclera são episclera, estroma e lâmina fosca. A episclera é constituída por tecido conjuntivo vascular denso que se origina do estroma escleral superficial e da cápsula de Tenon que a recobre. $\mathrm{O}$ estroma escleral, é constituído por fibras colágenas (10 - $15 \mu$ de espessura e 100 $150 \mu$ de comprimento) dispostas no padrão em xadrez irregular paralelo à superfície do globo. A lâmina fosca, camada mais interna, está em íntimo contato com a úvea e apresenta células pigmentadas.

A vascularização da episclera é oriunda do plexo episcleral superficial e profundo. O estroma escleral é avascular e o suprimento sanguíneo é dependente do plexo episcleral e da circulação da coróide. A camada episcleral superficial tem configuração radial e apresenta vasoconstrição com uso tópico de fenilefrina a $10 \%$. O plexo vascular profundo recobre a esclera e não apresenta resposta vasoconstritora com fenilefrina a 10\%. As veias episclerais realizam a drenagem sanguínea dos capilares episclerais e limbares.

A inervação de esclera é realizada pelos nervos ciliares posteriores longos e curtos, ramos do trigêmeo.

A função da episclera é de suporte nutricional da esclera, revestimento sinovial escleral e resposta inflamatória às agressões da esclera. A principal função da esclera é de proteção do conteúdo intra-ocular, sendo resistente e elástica. Possui atividade metabólica baixa, com nutrição através da vascularização episcleral e coroidal, sendo permeável à $\mathrm{H}_{2} \mathrm{O}$, glicose e proteína. A opacidade da esclera é devido à maior birrefringência das fibras esclerais, irregularidade de intervalos entre as fibras, variação maior no 
diâmetro da fibra e elevada hidratação. A esclera pode se tornar transparente quando desidratada (conteúdo da água < $40 \%$ ), como percebido nos afilamentos esclerais.

A estrutura colagenosa da esclera e o envoltório pela episclera são comparados à constituição sinovial, sugerindo analogia do olho com articulação esferoidal. Ressalte-se que doenças que acometem estruturas articulares geralmente atingem a bainha escleral-episcleral ${ }^{(1)}$.

\section{CLASSIFICAÇÃO}

As doenças clínicas mais freqüentes da esclera e episclera são inflamatórias, ocorrendo ainda enfermidades metabólicas, degenerativas, neoplásicas e por traumatismo.

As inflamações da esclera são divididas, com finalidade didática, de acordo com a camada acometida (Quadro 1). A episclerite é caracterizada por infiltração celular do tecido episcleral superficial e a esclerite por infiltração dos tecidos episcleral superficial, profundo e escleral. A classificação em esclerite anterior e posterior identifica sua localização anterior ou posterior ao equador do globo ocular ${ }^{(1)}$.

\section{EXAME OFTALMOLÓGICO}

O exame oftalmológico do paciente com inflamação escleral consiste na avaliação completa incluindo acuidade visual, motilidade ocular extrínseca, biomicroscopia e fundoscopia. $\mathrm{O}$ quadro 2 mostra um roteiro auxiliar para o diagnóstico diferencial das doenças inflamatórias.

A avaliação da episclera e esclera começa pelo exame externo a olho nu com boa iluminação: a episclerite apresenta olho vermelho e a esclerite, exibe um tom vermelho-azulado. Se há necrose escleral, aparecem áreas azul-acinzentadas ou marrom escuras, devido à visibilização do pigmento coroidal subjacente. Com a progressão da necrose escleral surgem áreas avasculares esbranquiçadas que podem desprender-se (áreas de seqüestro).

Na biomicroscopia à lâmpada de fenda, a avaliação das bordas superficial e profunda do feixe de luz incidente na área

\begin{tabular}{|ll|}
\hline \multicolumn{2}{|c|}{ Quadro 1 - Classificação clínica da episclerite e esclerite } \\
EPISCLERITE & $75 \%$ \\
simples & $25 \%$ \\
nodular & \\
ESCLERITE & 80 a $95 \%$ \\
Esclerite Anterior & $40 \%$ \\
difusa & $45 \%$ \\
nodular & $15 \%$ \\
necrotizante & \\
$\quad$ com inflamação & \\
sem inflamação - escleromalácia perfurante & 5 a $20 \%$ \\
Esclerite Posterior & \\
\hline
\end{tabular}

\begin{tabular}{|c|c|c|}
\hline \multicolumn{3}{|c|}{ Quadro 2 - Diferenciação entre episclerite e esclerite } \\
\hline & Episclerite & Esclerite \\
\hline Hiperemia & Vermelha & Vermelha-azulada \\
\hline Biomicroscopia & $\begin{array}{l}\text { Inflamação } \\
\text { episcleral }\end{array}$ & $\begin{array}{l}\text { Inflamação } \\
\text { episcleral e escleral }\end{array}$ \\
\hline Teste da fenilefrina $10 \%$ & $\begin{array}{l}\text { Diminui } \\
\text { a hiperemia }\end{array}$ & $\begin{array}{l}\text { Sem alteração acen- } \\
\text { tuada da hiperemia }\end{array}$ \\
\hline Mobilização do nódulo & Nódulo móvel & Nódulo imóvel \\
\hline Dor & Discreta & Severa \\
\hline Caráter da doença & Benigna & Grave \\
\hline Associação sistêmica & $32 \%$ & $75 \%$ \\
\hline Complicações oculares & Pouco freqüentes & Freqüentes \\
\hline
\end{tabular}

acometida auxilia o diagnóstico diferencial entre episclerite e esclerite. Na episclerite, há o deslocamento anterior da borda superficial do feixe de luz da lâmpada de fenda correspondente ao edema episcleral, porém não há elevação da borda profunda do feixe de luz, pois não há comprometimento escleral. $\mathrm{Na}$ esclerite há deslocamento anterior da borda superficial do feixe de luz (edema episcleral) e deslocamento anterior da borda profunda do feixe de luz (edema escleral).

O teste da fenilefrina a $10 \%$ é utilizado na diferenciação entre episclerite e esclerite, pois a fenilefrina apresenta maior efeito vasoconstritor no plexo episcleral superficial do que no episcleral profundo. Na episclerite, como há congestão do plexo episcleral superficial sem ou com pouco comprometimento do plexo profundo, após 10 minutos de instilação de 1 gota de fenilefrina a $10 \%$, a hiperemia ocular diminui significativamente. Na esclerite, por sua vez, o plexo episcleral profundo fica mais congesto que o plexo superficial e não se altera com instilação tópica de fenilefrina $10 \%$.

A instilação tópica de anestésico e mobilização do tecido episcleral com cotonete permite o diagnóstico diferencial entre episclerite nodular anterior (nódulo móvel) e esclerite nodular anterior (nódulo imóvel).

\section{QUADRO CLÍNICO}

\section{EPISCLERITE}

É uma doença benigna, aguda e autolimitada, que cursa com desconforto ocular, hiperemia e lacrimejamento com duração variável entre 2 a 21 dias. A sua freqüência é maior que a da esclerite, sendo que há relato de progressão de episclerite para esclerite em $0,3 \%$ dos casos.

A episclerite afeta principalmente mulheres jovens e de meia-idade, porém há casos descritos em crianças com idade a partir de 13 meses. Apresenta acometimento unilateral em até $2 / 3$ dos casos em adultos e $1 / 2$ dos casos em crianças $^{(2)}$. Pode apresentar recorrência no mesmo olho ou no contralateral. Há associação com doença sistêmica em aproximadamente 32\% dos casos, sendo as mais comuns doenças do tecido conjuntivo como artrite reumatóide, granulomatose de Wegener, pan- 
arterite nodosa, lupus eritematoso sistêmico ${ }^{(3)}$. As complicações oculares são pouco freqüentes e geralmente leves.

\section{Episclerite simples}

Apresenta hiperemia setorial e, às vezes, difusa da episclera. Geralmente é recorrente, benigna e idiopática (Figura 1).

\section{Episclerite nodular}

Inflamação episcleral localizada com hiperemia, edema e formação de nódulo que pode ser movimentado sobre a esclera. Tende a recorrer no mesmo local. Pode estar associada com doenças sistêmicas (Figura 2).

\section{ESCLERITE}

A esclerite é doença inflamatória grave, que cursa com quadro gradual de dor ocular severa, com característica de irradiação para face ipsilateral ${ }^{(4)}$. Acomete mais mulheres jovens

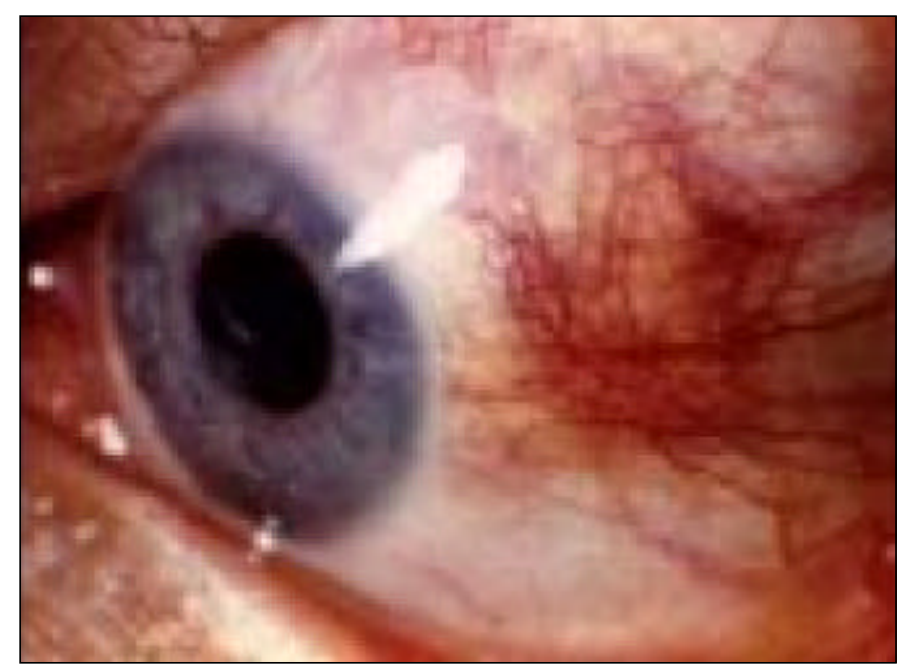

Figura 1 - Episclerite simples

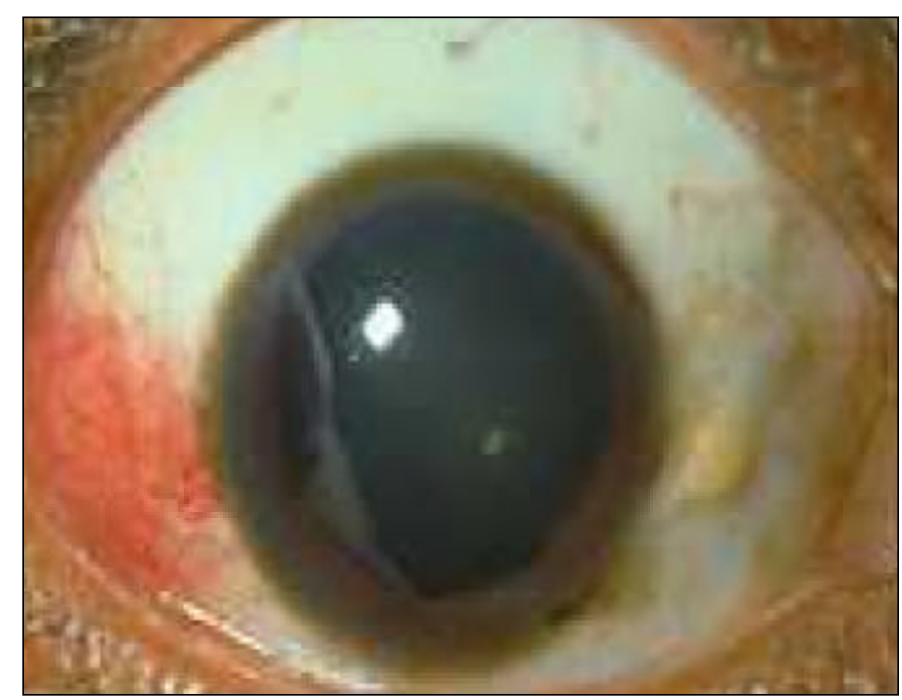

Figura 2 - Episclerite nodular e de meia-idade. Tem associação sistêmica freqüente com doenças sistêmicas reumatológicas $(75 \%)$, principalmente artrite reumatóide, granulomatose de Wegener, panarterite nodosa e lupus eritematoso sistêmico. Calcula-se que 1 em 200 pacientes com artrite reumatóide tenha esclerite. As complicações oculares são freqüentes e severas, podendo evoluir para perda ocular por perfuração, descolamento de retina, edema do nervo óptico, alterações corneanas, uveíte, glaucoma, entre outras $^{(5)}$.

\section{Esclerite anterior}

\section{Esclerite anterior difusa}

Apresenta hiperemia superficial e profunda associada a edema escleral, envolvendo uma parte ou toda a esclera. A distorção do plexo vascular é característica, com perda do padrão radial normal. É relativamente benigna e raramente progride para forma nodular (Figura 3 ).

\section{Esclerite anterior nodular}

É uma apresentação comum das doenças esclerais. Caracteriza-se por hiperemia e edema, com nódulo escleral localizado, doloroso e imóvel. A mobilidade do nódulo faz o diagnóstico diferencial com episclerite nodular anterior. É doença de severidade intermediária, podendo evoluir para necrose (Figura 4).

\section{Esclerite anterior necrotizante com inflamação}

É a forma mais severa de esclerite. O início é gradual, com dor e hiperemia ocular localizada. Freqüentemente a esclerite anterior necrotizante com inflamação está associada com doença do tecido conjuntivo soropositiva. Pode ser do tipo vasooclusiva ou granulomatosa. A esclerite necrotizante pode ser a manifestação inicial de uma doença sistêmica potencialmente letal. Ocorre a morte de $25 \%$ dos pacientes em 5 anos devido à doença sistêmica ${ }^{(1)}$ (Figura 5).

\section{$\underline{\text { Tipo vaso-oclusiva }}$}

Apesar de incomum, é de extrema gravidade. Apresenta-se

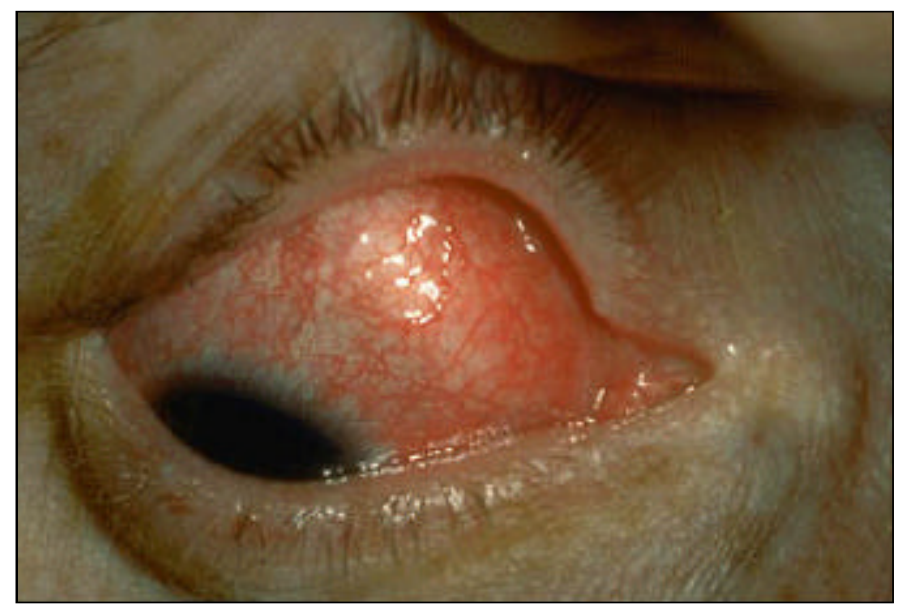

Figura 3 - Episclerite anterior difusa 


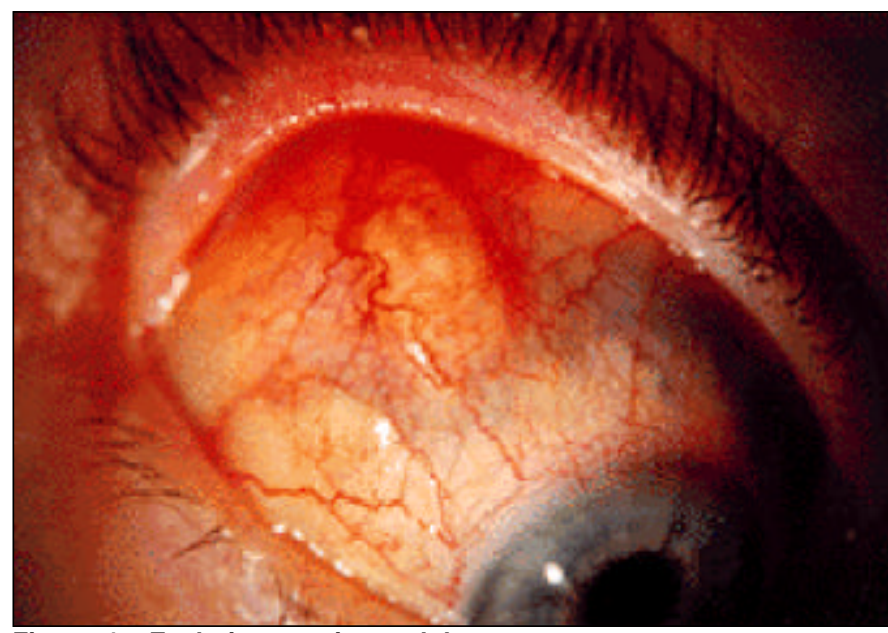

Figura 4 - Esclerite anterior nodular

com inflamação intensa similar a esclerite difusa, com distorção ou oclusão dos vasos, resultando em áreas avasculares que podem ser observadas ao exame biomicroscópico com maior aumento e filtro verde. Podem ocorrer simultaneamente em vários locais, geralmente na área entre os músculos retos. Se não houver controle, pode evoluir para necrose tecidual. A esclera afilada pode tornar-se transparente, com visibilização da úvea subjacente. A presença de uveíte anterior é indicativa de doença severa envolvendo o corpo ciliar.

\section{$\underline{\text { Tipo granulomatosa }}$}

É encontrada nas vasculites sistêmicas. O exame biomicroscópico com maior aumento e com uso de filtro verde evidencia superfície irregular repleta por pequenos vasos permeáveis. Pode haver fluxo diminuído ou ausente nos vasos episclerais remanescentes. Estas alterações são mais freqüentes e mais fáceis de serem detectadas no limbo. O sinal mais precoce é hiperemia ocular intensa e extravasamento plasmá-

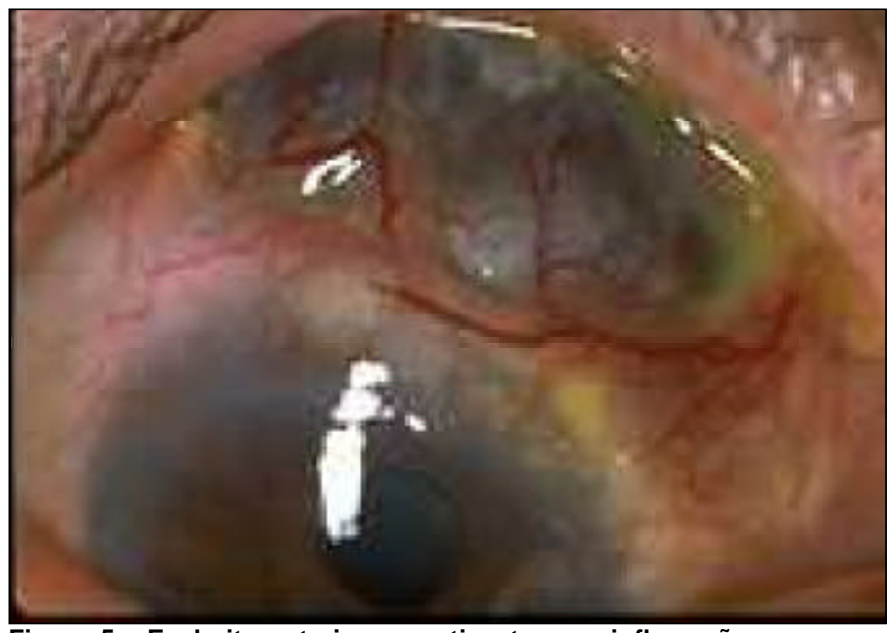

Figura 5 - Esclerite anterior necrotizante com inflamação tico das arcadas limbares, detectados como manchas acinzentadas de cada lado do capilar. Este sinal desaparece poucas horas após tratamento.

\section{Esclerite anterior necrotizante sem inflamação - Escleromalácia perfurante}

Este termo é usado para diagnosticar uma condição específica quase sempre associada a mulheres com artrite reumatóide soropositiva de longa duração. Os vasos conjuntivais e episclerais apresentam-se bastante estreitados e o tecido episcleral praticamente desaparece. O quadro é assintomático, com inflamação mínima e mudança da coloração da esclera para tom amarelado. Estas áreas amareladas desintegram e são absorvidas em aproximadamente 1 a 2 meses, com exposição da coróide subjacente (Figura 6). A perfuração espontânea é rara, podendo ocorrer praticamente sem sintomas.

O exame com UBM (biomicroscopia ultra-sônica) forma dados complementares para diagnóstico e análise da evolução destas doenças. Na episclerite há espessamento do tecido episcleral sem envolvimento da esclera. Na esclerite, há regiões de baixa refletividade dentro da esclera, representando edema e infiltrado inflamatório. A esclerite difusa é caracterizada por espessamento escleral heterogêneo de aspecto moteado. A esclerite nodular apresenta-se com lesão escleral bem delimitada, homogênea, hiporrefletiva, com espessamento localizado e hiporrefletividade dos tecidos adjacentes. A esclerite necrotizante cursa com perda de tecido e afinamento escleral, com alterações vítreas adjacentes.

\section{Esclerite posterior}

A inflamação do segmento escleral posterior corresponde de 5 a $20 \%$ das esclerites e geralmente é pouco diagnosticada. Acomete preferencialmente mulheres jovens e de meia-idade.

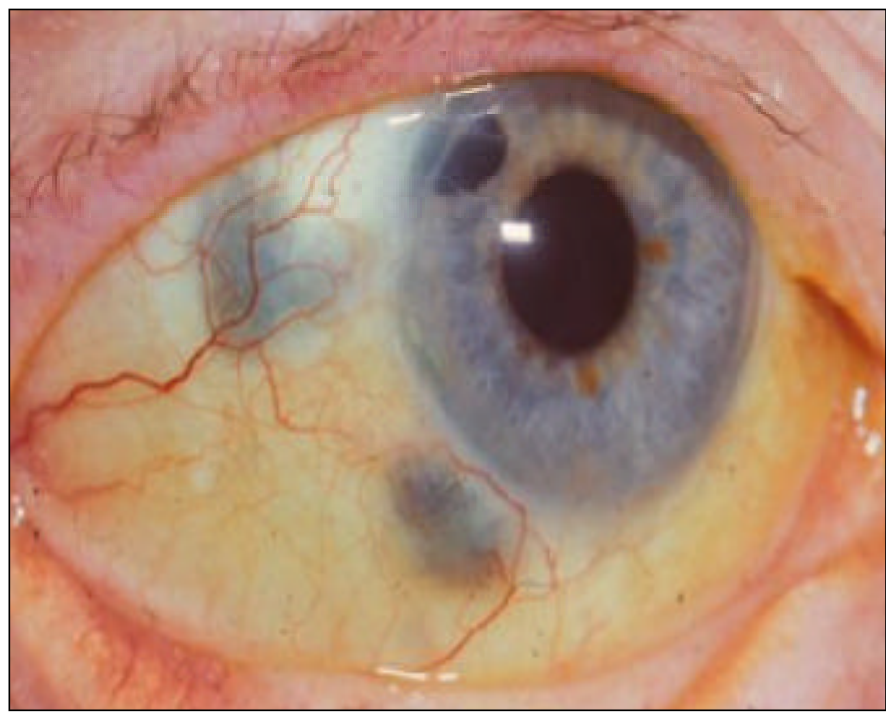

Figura 6 - Escleromalácia perfurante 
Acometimento bilateral ocorre em até $35 \%$ dos pacientes, e recorrência freqüente ${ }^{(6)}$.

O quadro pode começar com inflamação originalmente atrás do equador do globo ocular ou resultar da ser extensão da esclerite anterior.

As manifestações clínicas são variadas. Pode haver quadro com dor peri-ocular intensa, proptose, restrição da musculatura ocular extrínseca, baixa da acuidade visual e associação com esclerite anterior. Outro tipo de apresentação é um quadro indolor, com baixa da acuidade visual, pouco ou nenhum sinal inflamatório. A fundoscopia pode evidenciar edema do disco óptico, edema macular, descolamento de retina exsudativo. Outros achados são de vitreíte, descolamento anular da coróide, pregas coroidais, massa sub-retiniana, depósitos intraretinianos esbranquiçados semelhantes a exsudatos duros e exsudação sub-retiniana (Figura 7).

A ultra-sonografia ocular modo-B (ecografia) pode evidenciar espessamento escleral, fluido no espaço episcleral, distensão da bainha do nervo óptico, massa sub-retiniana e descolamento de retina exsudativo (Figura 8). É importante ressaltar que, em alguns pacientes, mesmo após a resolução clínica, os sinais ultra-sonográficos de massa residual ou edema persistem por um período variável.

A angiofluoresceinografia ocular permite avaliação do envolvimento coroidal, servindo como parâmetro para acompanhamento da doença e resposta ao tratamento. Ocorre hiperfluorescência difusa da coróide nas fases intermediária (10 minutos) e tardia (40 minutos) que tendem a regredir com o tratamento.

Os principais diagnósticos diferenciais da esclerite posterior são melanoma de coróide, celulite orbitária, oftalmopatia de Graves, trombose do seio cavernoso e fístula carótidocavenosa.

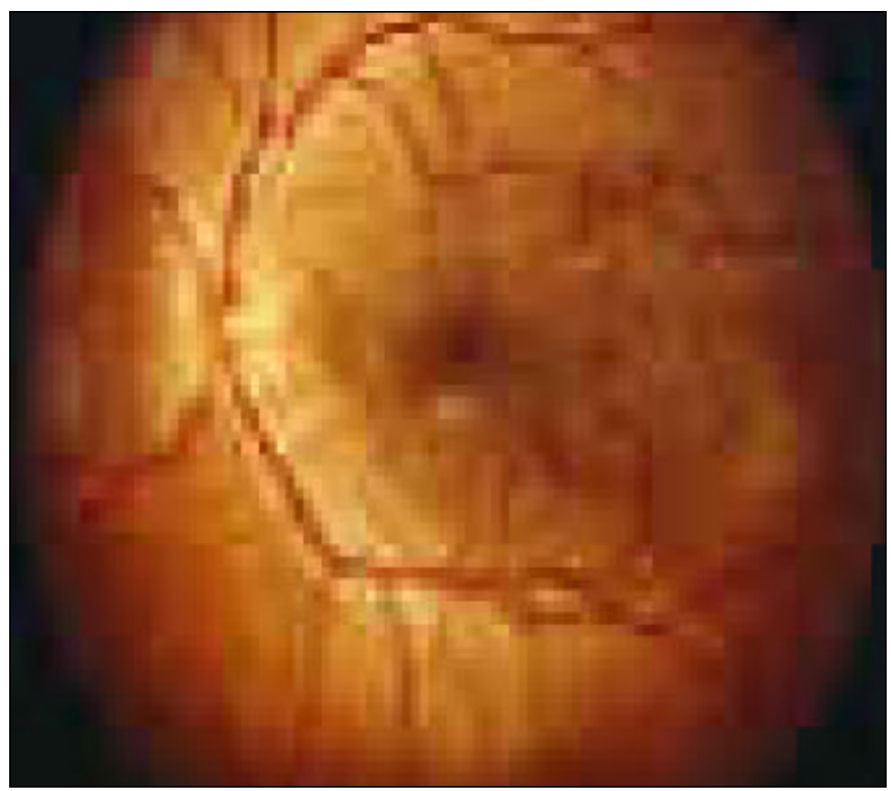

Figura 7 - Esclerite posterior

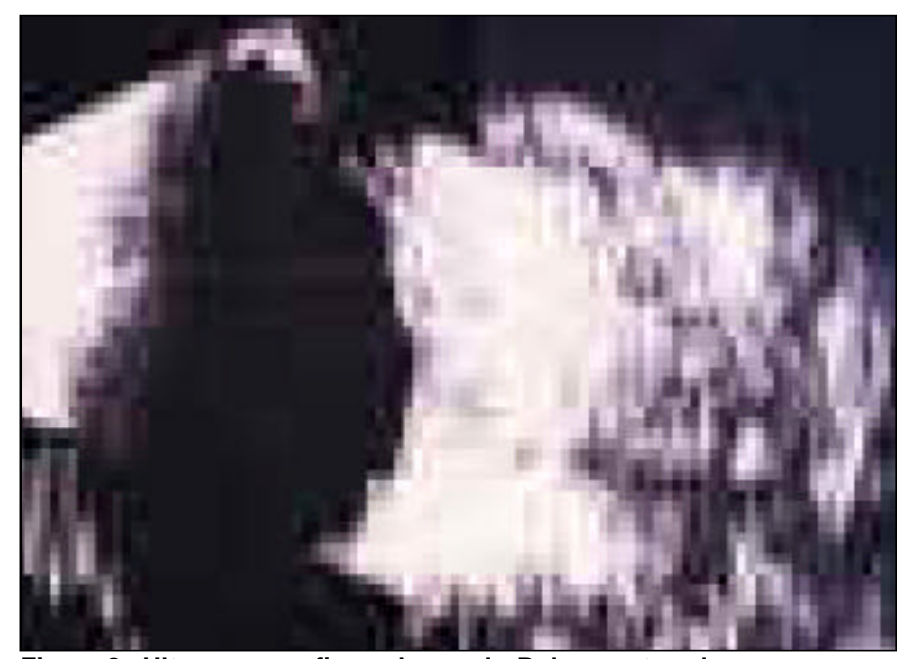

Figura 8 - Ultra-sonografia ocular modo-B demonstrando espessamento escleral com edema retrobulbar na esclerite posterior

A esclerite posterior pode ser idiopática ou associada a doenças sistêmicas reumatológicas (30\%). Os pacientes mais idosos têm maior probabilidade de associação com doença do tecido conjuntivo. A perda visual independe da idade, tipo ou apresentação da doença.

\section{INVESTIGACÃO DIAGNÓSTICA NAS EPISCLERITES E ESCLERITES}

A detecção da associação com doenças sistêmicas é importante para a conduta adequada das episclerites e esclerites:

\section{Episclerites}

Geralmente as episclerites podem apresentar associação com doenças sistêmicas (reumatológicas) em aproximadamente $32 \%$ dos casos e com doenças oculares em aproximadamente $50 \%$ dos casos (principalmente rosácea ocular, ceratoconjuntivite seca e ceratoconjuntivite atópica). A avaliação diagnóstica geralmente não é necessária para o primeiro episódio, porém episódios recorrentes ou persistência dos sintomas requerem avaliação clínica sistemática (avaliação dos sintomas, exame físico e testes diagnósticos). Não há associação entre tipo de episclerite, lateralidade ou recorrência com a presença de doença sistêmica associada.

As episclerites infecciosas são infreqüentes. Os casos descritos são decorrentes de infecção por hanseníase, brucelose, Herpes zoster, sífilis e doença de Lyme. O diagnóstico diferencial com episclerite inflamatória é difícil. Geralmente a suspeita diagnóstica é realizada quando não há melhora do quadro com tratamento anti-inflamatório e a sorologia é positiva para determinado agente etiológico.

\section{Esclerites}

As esclerites geralmente apresentam doenças associadas (75\% dos casos). As mais encontradas são: 
$48 \%$ - colagenoses (artrite reumatóide, granulomatose de Wegener, policondrite recidivante, espondilite anquilosante, síndrome de Reiter, artrite psoriática, artrite e doença inflamatória intestinal, pan-arterite nodosa, angeíte alérgica de Churg-Strauss, gota ${ }^{(7-9)}$

$7 \%$ - doença infecciosas: Pseudomonas aeruginosa, Haemophilus influenza, Mycobacterium leprae, Aspergilus, Acanthamoeba, Herpes zoster, parasitas ${ }^{(10-11)}$

$2 \%$ - rosácea, atopia, granuloma de corpo estranho, lesão química

A avaliação diagnóstica é importante em todos os casos de esclerite e inclui avaliação clínica geral, com interrogatório dos sistemas e investigação laboratorial. O quadro 3 orienta a investigação laboratorial para doenças sistêmicas. O encaminhamento para o reumatologista é aconselhável para cooperação no diagnóstico e tratamento. As doenças do tecido conjuntivo podem apresentar severidade variável. As espondiloartropatias (espondilite anquilosante, síndrome de Reiter, artrite psoriáticas, artrite e doença inflamatórias intestinais) tendem a cursar com esclerite mais benigna, a artrite reumatóide e lúpus eritematoso sistêmico com esclerite de severidade intermediária, enquanto a granulomatose de Wegener geralmente apresenta quadro severo de esclerite necrotizante e ceratite ulcerativa periférica ${ }^{(3)}$.

As esclerites ou ceratoesclerites infecciosas são geralmente devastadoras e de difícil erradicação. Os fatores predisponentes são história prévia de cirurgia ocular, trauma local, doença escleral ou imunossupressão. A destruição tecidual pode evoluir para necrose e infecção secundária. A cirurgia mais associada à esclerite infecciosa é exérese de pterígio com uso de mitomicina, tiotepa, betaterapia ou cauterização excessiva $^{(12)}$. Cirurgias de catarata, glaucoma ou descolamento de retina também podem estar associadas à esclerite infecciosa. O período de latência para infecção pode ser longo, com relatos de 1 semana a 32 anos. O agente mais associado é a Pseudomonas aeruginosa, seguido de S. pneumoniae, Staphilococcus aureus, Aspergilus, Mycobacterium fortuitum, H.influenzae, varicela-zoster, Treponema palidum, Acantamoeba, Nocardia, Actinomyces ou agentes mistos ${ }^{(13-16)}$.

O quadro clínico é de dor ocular de moderada à severa, edema palpebral, proptose, hiperemia ocular, lacrimejamento, fotofobia, associados ou não à baixa de acuidade visual. $\mathrm{O}$ exame biomicroscópico pode evidenciar ulceração no local da exérese do pterígio associada ou não à ulceração corneana periférica, nódulos esclerais múltiplos com epitélio conjuntival intacto. Acredita-se que os nódulos esclerais representem disseminação intra-escleral da infecção ou resposta auto-imune. Pode haver uveíte anterior e/ou esclerite posterior associadas. Após resolução da infecção, surgem afinamento e placas esclerais.

As complicações da esclerite infecciosa são freqüentes e graves. Há relatos de $75 \%$ de cegueira com ausência de percepção luminosa. Pode haver perda do olho pela infecção, perfuração, cicatrização corneana, catarata, descolamento de retina, descolamento de coróide, edema macular cistóide e recorrência de infecção, inclusive na área não acometida previamente. A disseminação da infecção para o sistema nervoso central pode ser fatal.

O diagnóstico diferencial entre esclerite necrotizante inflamatória e infecciosa é difícil. Os casos de esclerite infecciosa descritos na literatura inicialmente foram tratados como esclerite inflamatória e diante da progressão da esclerite a despeito da terapia imunossupressora, foram posteriormente investigados e diagnosticados como esclerite infecciosa. Sugere-se

\section{Quadro 3 - Investigação laboratorial para doenças sistêmicas}

\begin{tabular}{ll} 
Doenças & \multicolumn{1}{c}{ Investigação clínica } \\
Artrite reumatóide & $\begin{array}{l}\text { Fator Reumatóide, anticorpo antinuclear-ANA (anti-DNA-histona), coagulograma, complemento, } \\
\text { crioglobulinas, radiografia dos membros, tipagem HLA }\end{array}$ \\
$\begin{array}{ll}\text { Lupus eritematoso sistêmico } & \text { Anticorpo antinuclear-ANA (anti-DNAds, anti-Sm), coagulograma, complemento, crioglobulina, } \\
\text { análise urinária }\end{array}$ \\
$\begin{array}{ll}\text { Espondilite anquilosante } & \text { CIC, radiografia sacro-ilíaca, tipagem HLA } \\
\text { Síndrome de Reiter } & \text { CIC, radiografia sacro-ilíaca, tipagem HLA, análise urinária } \\
\text { Artrite psoriática } & \text { Radiografia sacro-ilíaca e dos membros } \\
\text { Artrite e doença inflamatória intestinal } & \text { Radiografia abdominal, sacro-ilíaca e dos membros } \\
\text { Policondrite recidivante } & \text { Coagulograma, complemento, anticorpos anti-colágeno tipo II } \\
\text { Pan-arterite nodosa } & \text { AgHBs, crioglobulina, coagulograma, complemento, angiografia, análise urinária } \\
\text { Síndrome de Churg-Strauss } & \text { Leucograma (eosinófilos), IgE, coagulograma, radiografia pulmonar } \\
\text { Granulomatose de Wegener } & \text { IgA, IgE, fator reumatóide, anticorpo citoplasmático anti-neutrófilo-ANCA, coagulograma, radiografia } \\
\text { pulmonar e dos seios da face, uréia/creatinina, clearence de creatinina, análise urinária }\end{array}$ \\
$\begin{array}{l}\text { Doença de Behçet } \\
\text { Arterite de células gigantes }\end{array}$ & Coagulograma, complemento, tipagem HLA \\
Síndrome de Cogan & VHS, IgG, coagulograma \\
Atopia & Coagulograma, complemento \\
Gota & Leucograma (eosinófilos), IgE, radiografia pulmonar \\
Infecciosa & Ácido úrico, radiografia dos membros \\
\hline
\end{tabular}


que o diagnóstico de esclerite infecciosa seja aventado nos casos de esclerite necrotizante com fator de risco para infecção. A cultura externa da lesão geralmente não é efetiva na identificação do agente, devendo ser realizada biópsia dos nódulos esclerais.

\section{COMPLICAÇÕES OCULARES NAS EPISCLERITES E ESCLERITES ${ }^{(17-18)}$}

\section{Episclerites}

As complicações oculares são incomuns:

a) alterações corneanas

- dellen secundário a elevação do limbo por edema ou nódulo episcleral. Melhora com curativo oclusivo, lubrificação ou com a resolução do edema.

- inflamação significativa pode resultar em infiltração estromal média ou superficial, edema corneano e vascularização.

b) uveíte - 7 a 11,4\%

c) glaucoma $-7,8 \%$

\section{Esclerites}

As complicações oculares são freqüentes:

a) alterações corneanas

a.1) nas esclerites difusa e nodular podem ocorrer alterações corneanas em $37 \%$ dos casos de, com quatro padrões de acometimento corneano:

- ceratite estromal difusa: opacidades mesoestromais com padrão imune e precipitados ceráticos.

- ceratite estromal esclerosante: edema, inflamação estromal, vascular e cicatrizes resultando em formação cristalina.

- ceratite profunda: lâminas brancas e opacas de infiltração na membrana de Descemet

- sulcos límbicos: sulcos límbicos evoluem para ectasia, caracterizados por depósitos lipídicos com ou sem vascularização.

a.2) na esclerite necrotizante, as alterações corneanas são mais graves, ocorrendo basicamente em três formas:

- ceratite estromal aguda: edema, infiltração branca e densa associada a infiltrados anulares e precipitados ceráticos.

- sulcos corneanos: adelgaçamento marginal com inflamação proeminente indicativa de vasculite, apresentando diagnóstico diferencial com úlcera de Mooren.

- ceratólise: áreas difusas de infiltração corneana que se adelgaçam devido à dissolução estromal, resultando em descemetocele circundada por tecido vascularizado e cicatrizes irregulares.

b) uveíte $35 \%$

c) adelgaçamento escleral $27 \%$

d) glaucoma (ângulo aberto e fechado) 13,5\%

e) outros: catarata, descolamento de retina, edema do nervo óptico, perfuração ocular e phthisis bulbi

\section{TRATAMENTO}

\section{Episclerite}

A maioria dos casos de episclerite não nodular resolve-se espontaneamente em 1-2 semanas. O tratamento geralmente é sintomático com compressas frias e lágrimas artificiais geladas. Corticosteróides tópicos diminuem os sintomas e abreviam o tempo de resolução, mas são vistos com ressalva pela possibilidade de recorrência do processo por efeito rebote. Antiinflamatório não-hormonal sistêmico e/ou locais são outra opção terapêutica.

As episclerites infecciosas são tratadas de acordo com o agente etiológico identificado.

\section{Esclerite}

O tratamento das esclerites difusa e nodular é realizado inicialmente com anti-inflamatórios não-hormonais sistêmicos. Em casos de resistência ao tratamento inicial, deve-se optar pela prescrição de corticóides sistêmicos. O tratamento com corticóide tópico tem pouco resultado clínico.

Casos de esclerite difusa ou nodular resistentes a corticoterapia sistêmica ou casos de esclerite necrotizante tem indicação de quimioterapia sistêmica. O tratamento deve ser realizado conjuntamente com hematologistas ou oncologistas.

Casos de esclerite necrotizante progressiva com necrose escleral podem necessitar de transplante escleral e quimioterapia sistêmica.

Na esclerite anterior necrotizante sem inflamação (escleromalácia perforans) não há tratamento eficaz para o quadro ocular, sendo a terapia direcionada para a doença reumatológica e para as complicações oculares.

A maioria dos casos de esclerite posterior resolvem com o uso de anti-inflamatório não-hormonal sistêmico. Pacientes com perda visual, envolvimento do nervo óptico ou doença sistêmica associada necessitam de anti-inflamatório hormonal sistêmico e, os casos resistentes podem necessitar de quimioterapia sistêmica.

As esclerites e ceratoesclerites infecciosas são de difícil tratamento. A penetração do antibiótico na esclera é baixa e a persistência do microorganismo nas lamelas avasculares intra-esclerais sem incitar resposta inflamatória dificulta a resolução da infecção. O tratamento com antibiótico tópico geralmente é ineficaz. A associação cirúrgica ao tratamento tem evidenciado melhores resultados prognósticos nas esclerites infecciosas. $\mathrm{O}$ tratamento proposto é ressecção conjuntival com crioterapia da esclera subjacente associada ou não a transplante escleral ou córneo-escleral ${ }^{(19)}$. Os tecidos utilizados para recomposição escleral são esclera autóloga ou homóloga, fáscia lata, periósteo, derme, tecido sintético (goretex) ou tecido aórtico ${ }^{(20)}$. Há relatos de melhora da esclerite infecciosa com tratamento tópico e venoso prolongados com 


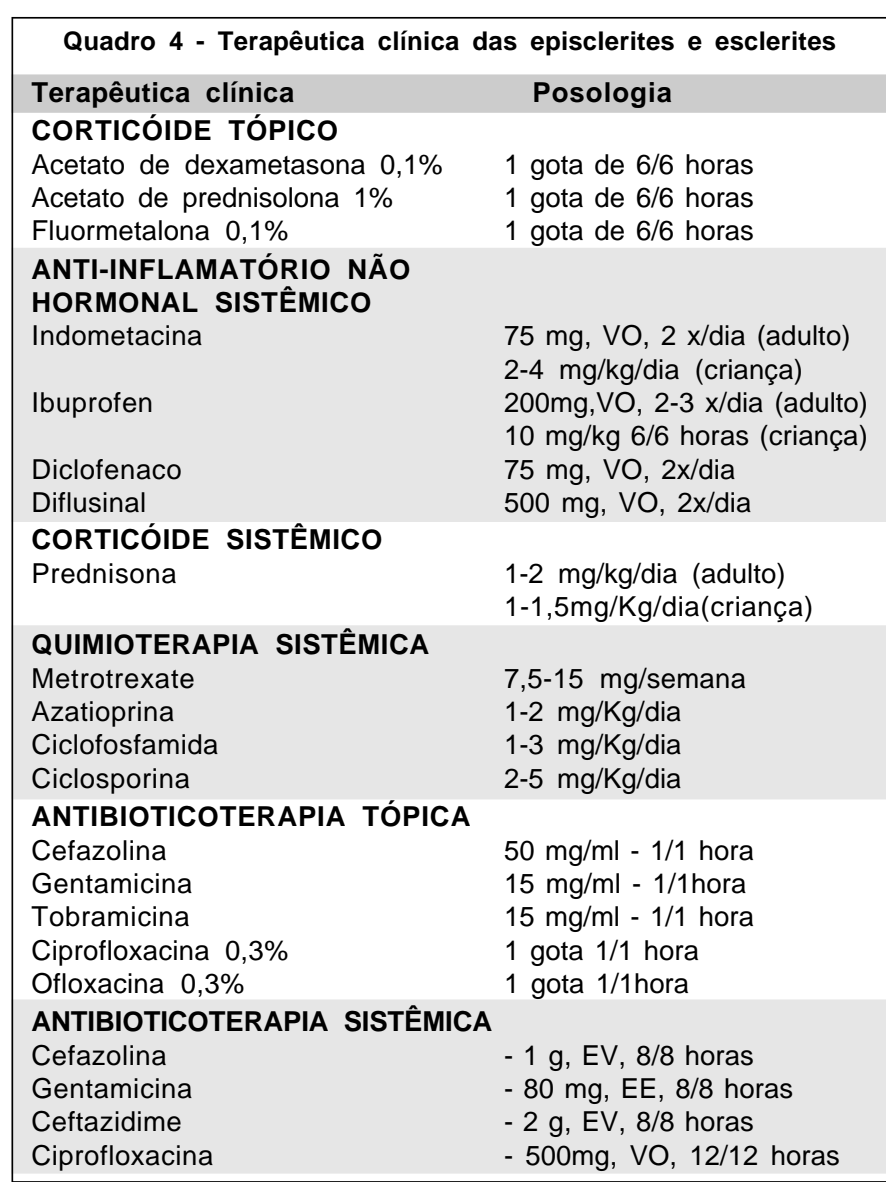

ceftazidime e aminoglicosídeo, sem necessidade de intervenção cirúrgica ${ }^{(21)}$. O uso do corticóide é controverso. Acreditase que a ação seja pouco benéfica no controle da inflamação, podendo facilitar evolução da infecção e sua recorrência tardia. Há autores que preconizam uso do corticóide apenas após identificação do microorganismo e tratamento antibiótico prévio adequado. $\mathrm{O}$ quadro 4 apresenta a posologia das medicações utilizadas no tratamento das episclerites e esclerites.

\section{AGRADECIMENTOS}

Aos Médicos Residentes da UNICAMP: William dos Santos Vinhadeli e Maurício Donatti

\section{ABSTRACT}

The most frequent scleral diseases are inflammatory, divided into episcleritis and scleritis. Episcleritis is a benign disease, with inflammatory response of the superficial episcleral tissue. On the other hand, scleritis is a progressive severe disease, with inflammatory response of superficial, deep epis- cleral and scleral tissues. The association with systemic rheumathological diseases requires systematic clinical approach of patients with scleral inflammation.

Keywords: Scleritis/diagnosis; Scleritis/drug therapy; Inflammation; Sclera/pathology; Bacterial eye infections/diagnosis; Bacterial eye infections/drug therapy; Autoimmune diseases/ diagnosis; Rheumatoid arthritis/complications; Adrenal cortex hormones/therapeutic use; Prednisolone/therapeutic use; Differential diagnosis; Treatment outcome

\section{REFERÊNCIAS}

1. Foster CS, Maza MS, Sangwan V, Watson PG, Pavésio C. Scleritis diagnosis and treatment. In: Annual Meeting. American Academy of Ophthalmology. Orlando, Flórida. October 24-27,1999.

2. Read RW, Weiss AH, Sherry DD. Episcleritis in childhood. Ophthalmology 1999;106:2377-9.

3. Akpek EK, Uy HS, Christen W, Gurdal C, Foster CS. Severity of episcleritis and systemic disease association. Ophthalmology. 1999;106:729-31.

4. Riono WP, Hidayat AA, Rao NA. Scleritis: a clinicopathologic study of 55 cases. Ophthalmology. 1999;106:1328-33.

5. José NK, Usuba FS. Alterações oculares em doenças reumatológicas. In: Cossermelli W. editor. Terapêutica em reumatologia. São Paulo: Editora Lemos; 2000;1207-16.

6. McCluskey PJ, Watson PG, Lightman S, Haybittle J, Restori M, Branley M. Posterior scleritis: clinical features, systemic associations, and outcome in a large series of patients. Ophthalmology. 1999;106:2380-6.

7. Olivalves SMR, Petrille AMN, Martins MC, Kim MK, Abreu, MT, Hilário, ME, Rolim MAS.Uveíte associada a artrite reumatóide juvenil. Arq Bras Oftalmol 1993;56:263-5.

8. Orefice F, Carvalho MAP, Moreira C. Doenças reumáticas In: Orefice F, Belfort Júnior R. Uveítes. São Paulo: Roca; 1987. p.171-85.

9. Orefice F, Carvalho MAR. Uveítes e artrites. Arq Bras Oftalmol 1995;48:123-9.

10. Carvalho AZ, Orefice,F. Inquérito tuberculínico. Estudo realizado em portadores de uveítes, esclerites e episclerites de causa endógena [tese].Belo Horizonte, Faculdade de Medicina da UFMG. 1986. 184p.

11. Fernandes JM, Orefice F, Carvalho AZ. Escleroceratouveíte na presença de tuberculose ganglionar. Arq Bras Oftalmol 1984;47:103-6,1984.

12. Alsagoff Z, Tan DT, Chee SP. Necrotising scleritis after bare sclera excision of pterygium. Br J Ophthalmol. 2000;84:1050-2.

13. Sykes SO, Riemann C, Santos CI, Meisler DM, Lowder CY, Whitcher JP, Cunningham ET. Haemophilus influenzae associated scleritis. Br J Ophthalmol 1999;83:410-3.

14. Livir-Rallatos C, El-Shabrawi Y, Zatirakis P, Pellett PE, Stamey FR, Foster CS. Recurrent nodular scleritis associated with varicella zoster virus. Am J Ophthalmol. 1998;126:594-7.

15. Casey R, Flowers CWJr, Jones DD, Scott L. Anterior nodular scleritis secondary to syphilis. Arch Ophthalmol. 1996;114:1015-6.

16. Knox CM, Whitcher JP, Cevellos V, Margolis TP, Irvine AR. Nocardia scleritis. Am J Ophthalmol. 1997;123:713-4.

17. Wirostko WJ, Wirostko E. Scleritis-associated uveitis [commented on Ophthalmology 1997;104:58-63]. Ophthalmology 1997;104:1207-8.

18. Sainz de la Maza M, Foster CS, Jabbur NS. Scleritis-associated uveitis [commented on Opthalmology 1997;104:1207-8]. Ophthalmology 1997;104:58-63.

19. Matayoshi S, Romeo SML, Prata Júnior J, Alves, MR. Tratamento cirúrgico da necrose da esclera após exérese de pterígio. Arq Bras Oftalmol 1994;57:185-9.

20. Matayoshi S, Alves MR, Araf, D. Periósteo autógeno no tratamento da necrose da esclera após exérese de pterígio e betaterapia. Arq Bras Oftalmol 1996;59:251-4.

21. Helm CJ, Holland GN, Webster RG Jr, Maloney RK, Mondino BJ. Combinationlintravenous ceftazidime and aminoglycosides in the treatment of pseudomonal scleritis. Ophthalmology 1997;104:838-43. 